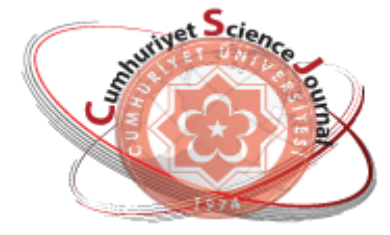

e-ISSN: $2587-246 X$

ISSN: $2587-2680$

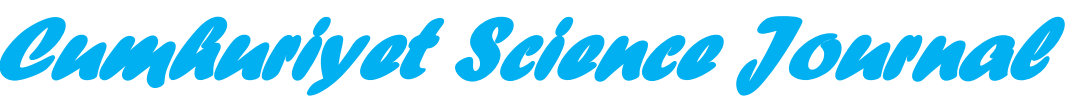

esJ

Cumhuriyet Sci. J., Vol.39-3(2018) 771-778

\title{
Determination of Polycyclic Aromatic Hydrocarbons Level in Commercial Turkish Milks
}

\author{
Sibel KAÇMAZ \\ Giresun University, Faculty of Engineering, Department of Food Engineering, Giresun, TURKEY \\ Received: 13.07.2018; Accepted: 19.09.2018 \\ http://dx.doi.org/10.17776/csj.443430
}

\begin{abstract}
In the present study, the presence of polycyclic aromatic hydrocarbons (PAHs) in commercial Turkish Milks was investigated. A total of 27 samples consisting of raw milk $(n=2)$, pasteurized milk $(n=5)$, UHT milk $(\mathrm{n}=17)$ and also plant milk $(\mathrm{n}=3)$ were analyzed for four EU marker polycyclic aromatic hydrocarbons (PAHs) by using a reversed phase high-performance liquid chromatography with fluorescence detection (HPLC-FLD).

The method was in house validated using the validation parameters such as linearity, precision (repeatability and intermediate precision), limit of detection (LOD) and limit of quantification (LOQ), recovery percentages, and also measurement uncertainty.

The mean concentrations of the sum of 4 EU marker PAHs were found $0.10 \pm 0.06 \mu \mathrm{g} \mathrm{kg}^{-1}, 0.71 \pm 0.33 \mu \mathrm{g} \mathrm{kg}$ ${ }^{1}, 0.84 \pm 0.57 \mu \mathrm{g} \mathrm{kg}^{-1}$ and $0.20 \pm 0.28 \mu \mathrm{g} \mathrm{kg}^{-1}$ for raw, pasteurized, UHT whole and plant milks, respectively. The analyzed milk samples did not exceed the maximum limits of $1.0 \mu \mathrm{g} \mathrm{kg}^{-1}$, that was regulated for both BaP and 4 EU marker PAHs (4 PAHs) by the European Union.
\end{abstract}

Keywords: PAHs, Milk, Extraction of PAHs, PAHs analysis, HPLC Analysis.

\section{Ticari olarak satılan Türk Sütlerinde Polisiklik Aromatik Hidrokarbon Seviyelerinin Belirlenmesi}

\footnotetext{
Özet. $\mathrm{Bu}$ çalı̧̧mada, ticari olarak satılan Türk sütlerinde polisiklik aromatik hidrokarbon $(\mathrm{PAH})$ varlı̆g 1 araştırılmıştır. Çiğ süt $(\mathrm{n}=2)$, pastörize süt $(\mathrm{n}=5)$, UHT süt $(\mathrm{n}=17)$ ve ayrıca bitki sütü $(\mathrm{n}=3)$ olmak üzere toplam 27 ticari süt örneğinde, $4 \mathrm{AB}$ öncelikli polisiklik aromatik hidrokarbon (PAH) yüksek performans siv1 kromatografisi-floresans dedektör kullanılarak (HPLC-FLD) tayin edilmiştir.

Yöntem, doğrusallık, kesinlik (tekrarlanabilirlik ve orta kesinlik), Tespit Limiti (LOD) ve Tayin Limiti (LOQ), geri kazanım ve ayrıca ölçüm belirsizliği gibi validasyon parametreleri kullanılarak doğrulanmıştır.

Dört AB öncelikli PAH (4PAH) toplamının ortalama konsantrasyonları, çiğ, pastörize, UHT ve bitki sütleri için, sırasıyla $0.10 \pm 0.06,0.71 \pm 0.33,0.84 \pm 0.57$ ve $0.20 \pm 0.28 \mu \mathrm{g} \mathrm{kg}^{-1}$ olarak bulunmuştur. Analiz edilen süt örnekleri, Benzopiren (BaP) ve $4 \mathrm{AB}$ öncelikli poliaromatik hidrokarbon (4PAH) için Avrupa Birliği tarafından belirlenen $1.0 \mu \mathrm{g} \mathrm{kg}^{-1}$ 'lık maksimum limitlerin altında olduğu görülmüştür.
}

Anahtar Kelimeler: PAH, Süt, PAH ekstraksiyonu, PAH analizi, HPLC

\section{INTRODUCTION}

Polycyclic aromatic hydrocarbons (PAHs), a part of chemical compounds with the inclusion of two or more aromatic rings, are ubiquitous in environment. PAHs are largely produced from pyrolytic processes, particularly the incomplete combustion of organic substances during industrial processes and other human activities such as coal processing, vehicle traffic, cooking, 
and tobacco smoking and also food processing such as barbecuing, baking, frying, roasting and smoking [1-4]. PAHs are harmful to human health, and some of them are classified mutagenic, carcinogenic, and as well as genotoxic $[5,6]$.

According to EC Scientific Committee report on Food that was published in 2002 (SCF) [1,2], 15 PAHs have major concern for human health and should be monitoring in foodstuffs. Afterwards, based on the occurrence and relative carcinogenicity evaluation of these 15 PAHs by IARC (The International Agency for Research on Cancer), the toxicological importance was confirmed $[5,6]$. Therefore, Scientific Committee of European Commission proposed further investigation into the levels of benzo[a]pyrene and other carcinogenic PAHs in certain foods [7].

In 2011, European Commission according to EFSA (European Food Safety Authority) report [8,9], stated in the Regulation (EU) No. 835/2011 that benzo[a]pyrene alone cannot be a sufficient marker for PAH occurrence in food, sum of a set of 4 PAHs (Chrysene (CHR), Benzo[b] fluoranthene $(\mathrm{BbF})$, Benz[a]anthracene $(\mathrm{BaA})$, and also Benzo[a]pyrene $(\mathrm{BaP}))$ is the most suitable criterion to understand PAHs behavior in food and specified the current maximum limits (MLs) in the same Regulation (EU) No. 835/2011 [10].

The regulation maintains an individual maximum limits (ML) for $\mathrm{BaP}$ and the sum of the 4 PAHs for 10 food categories such as oils and fats, smoked meat and smoked meat products, cocoa beans and products, muscle meat of smoked fish and smoked fishery products, processed cerealbased foods and baby foods but, there is no ML is established for milk and milk products. It is just specified as the maximum limits (MLs) for infant milk and follow-on milk that settled as $1 \mu \mathrm{g} \mathrm{kg}^{-1}$ for $\mathrm{BaP}$ and the sum of the 4 PAHs.

There are various studies in the literature from different country that confirmed PAHs contamination in commercial milks [11-16], but data are lacking for commercialized samples in Turkey.
The objective of this study was to investigate the concentration of PAHs in commercialized milk samples in Turkey. The used method is based on liquid-liquid extraction of PAHs (saponification of milk samples with $\mathrm{NaOH}$ ethanolic solution), a pre-concentration and determination by using a reversed phase high-performance liquid chromatography with fluorescence detection (HPLC-FLD). The method used was in house validated with the performance parameters such as linearity, repeatability, and intermediate precision, limits of detection (LOD) and quantification (LOQ), percentages of extraction recovery and as well as measurement uncertainty.

The present study indicated that the PAHs concentration in milk varied according to sample source. So, PAH distribution can be attributed to the different environmental pollution exposure or to the proses of heating to milk.

\section{MATERIALS AND METHODS}

\subsection{Chemicals}

A pure reference standard solution of Benzo[a]pyrene (BaP), Chrysene (CHR), Benz[a]anthracene $(\mathrm{BaA}), \quad$ and Benzo[b] fluoranthene $(\mathrm{BbF})(10 \mu \mathrm{g} / \mathrm{mL}$ in acetonitrile) were provided by the IRMM (Institute for Reference Materials and Measurements, Geel, Belgium).

All solvents, acetonitrile (99.9\%), cyclohexane ACS (>99.5\%) and ethanol used were of analytical grade, were purchased from Sigma Aldrich (Steinheim, Germany). $\mathrm{NaOH}$ was purchased by Merck (Darmstadt, Germany). 0.45 $\mu \mathrm{m}$ PTFE acrodisc (Polytetrafluoroethylene, 25 $\mathrm{mm}$ i.d.) syringe filters were purchased from Sigma Aldrich (Steinheim, Germany). Ultrapure water generated by a Milli-Q de-ionized water unit by Millipore Co. (Bedford, MA, USA).

\subsection{Sampling}

This study was conducted on a total 27 milk samples that comprise 2 raw cow's milk, 5 pasteurized cow's milk, 10 UHT whole and 4 UHT semi-skimmed, 3 UHT skimmed milk and 
also 3 plant milk samples (almond, soya and coconut milk). All milk samples which selected from the most popular commercial brands, were purchased from local dairy firms and supermarkets in the Black sea Region of Turkey during the months of March 2017 as would be done by a consumer. The packs size was from 200 to $1000 \mathrm{ml}$. Whole samples of milks were analyzed within the shelf life of the product.

\subsection{Sample preparation}

A sample preparation and extraction method described and optimized by Girelli et. all [11] was used. $2 \pm 0.1 \mathrm{~g}$ samples were first weighed into a 10-ml glass vial. These samples were saponificated with $\mathrm{NaOH}$ ethanolic solution (4.0 $\mathrm{mL}$ of $0.4 \mathrm{M}$ ). The glass vial was covered with aluminum foil to avoid daylight. Then it was waited for $30 \mathrm{~min}$ in a water bath at $60^{\circ} \mathrm{C}$. After addition of $2.0 \mathrm{ml}$ cyclohexane, the mixture was vortexed for $5 \mathrm{~min}$. The supernatant portion of the extracts were taken and transferred into a vial, this procedure was repeated two more times with $2 \mathrm{ml}$ cyclohexane. Finally, the combined extracts were filtered by using $0.45 \mu \mathrm{m}$ disk syringe filters and were evaporated until dryness under nitrogen to eliminate the solvents. The PAH residual was dissolved in $100 \mu \mathrm{l}$ acetonitrile. $20 \mu \mathrm{l}$ of this solution was injected into the HPLC system. A procedural blank (PB), constituted by $2 \mathrm{ml}$ of deionized water, and was simultaneously performed by the same procedure above described, with each series of samples.

\subsection{Equipment and Chromatographic conditions}

A high performance liquid chromatography (HPLC) (Agilent, 1260 infinity) system, consist of a 110 series fluorescence detector and a 7125 injector with a $20 \mu 1$ sample loop was used in this study (Santa Clara, CA, USA). Separation of PAHs was achieved by a LiChrospher C18 analytical column $(4.6 \mathrm{~mm} \times 250 \mathrm{~mm}, 5 \mu \mathrm{m})$ (Merck-Millipore, Millipore Corporation, Darmstadt, Germany) maintained at room temperature. A flow rate of $1.8 \mathrm{~mL} \mathrm{m^{-1 }}$ was selected. The gradient elution procedure was used by using solvent of water (A) and acetonitrile (B).

The gradient elution programme was set as follows: $60 \% \mathrm{~B}$ to $63 \% \mathrm{~B}(0-20 \mathrm{~min}), 63 \% \mathrm{~B}$ to $72 \%$ B (20-24 min), $72 \%$ B to $85 \%$ B (24-25) $\mathrm{min}), 85 \% \mathrm{~B}$ to $100 \% \mathrm{~B}$ (25-27 min), $100 \% \mathrm{~B}$ (27- $28 \mathrm{~min}$ ) and $100 \% \mathrm{~B}$ to $60 \% \mathrm{~B}(28-35 \mathrm{~min})$. 4 EU marker PAHs can be separated convincingly within $30 \mathrm{~min}$ with these conditions. The Fluorescence detection was performed by wavelength was set 260/420 (emission and excitation wavelength) $\mathrm{nm}$ to determine individual PAHs.

\section{RESULTS AND DISCUSSION}

\subsection{Analytical method performance}

The performance of the HPLC-FLD method was assessed for milk samples by establishing some quality parameters which is specified in internationally accepted guidance documents (Eurachem Guide) [17,18]. For validation of analytical procedure, linearity, selectivity, limit of detection (LOD), and limit of quantification (LOQ), repeatability and intermediate precision, recovery and as well as measurement uncertainty were evaluated.

Linearity of analytical procedure was evaluated by using the calibration function for each analyte, obtained from eight calibration points' signals, by visual inspection of the plot of residuals by fitting test of Mandel's [19,20]. Mandel's tests were passed, and for the four target analytes, there was no trend observed in any of the residual plots. As seen in Table 1, calibration curves that linear between 0.4 and $42 \mu \mathrm{g} \mathrm{kg}^{-1}$ were characterized with high correlation coefficients value $\left(\mathrm{R}^{2}>\right.$ 0.99 ) for each of investigated analyte.

Selectivity of the analytical procedure was evaluated by using the procedural blank reagent (PB) that was checked for interferences at the expected retention time of the analytes. For preparation of procedural blank reagent, extraction solvent $(2 \mathrm{ml})$ was used as sample and the whole analysis procedure was simultaneously 
performed with each series of sample. Selectivity can be defined acceptable in the form of an absence of peaks in the chromatogram of the procedural blank sample at the retention time of the analytes \pm 0.1 min whether peaks did not pass over $30 \%$ of the height of the native analyte in the chromatogram of the lowest calibration level [21]. As seen in table 1, Spectral interference at the retention time of the each analytes was between $12 \%$ and $28 \%$ of the peak heights of analyte peaks at the lowest calibration level that all of them were acceptable.
The limit of detection (LOD) and the limit of quantification (LOQ), defined as the concentration of the analyte that was produced a signal-to-noise ratio of 3 and 10, respectively. The LOD and LOQ were ranged from 0.04 to $0.12 \mu \mathrm{g} \mathrm{kg}^{-1}$ and from 0.12 to $0.40 \mu \mathrm{g} \mathrm{kg}^{-1}$ respectively (See Table 1 ).

Table 1 Correlation coefficients, linearity ranges, limit of detection (LOD), limit of quantification (LOQ) and selectivity parameter (Height PB/CS1 (\%)

Table 1. Correlation coefficients, linearity ranges, limit of detection (LOD), limit of quantification (LOQ) and selectivity parameter (Height PB/CS1 (\%).

\begin{tabular}{ccccccc}
\hline PAHs Compounds & $\mathrm{R}^{2}$ & $\begin{array}{c}\text { Linearity } \\
\left(\mu \mathrm{kg}^{-1}\right)\end{array}$ & Mandel's test & $\begin{array}{c}\text { LOD } \\
\left(\mu \mathrm{kg}^{-1}\right)\end{array}$ & $\begin{array}{c}\text { LOQ } \\
\left(\mu \mathrm{g} \mathrm{kg}^{-1}\right)\end{array}$ & $\begin{array}{c}\text { *Height PB/CS1 } \\
(\%)\end{array}$ \\
\hline Benz[a]anthracene & 0.9998 & $0.4-42$ & Passed & 0.04 & 0.12 & 28 \\
Chrysene & 0.9997 & $0.4-42$ & Passed & 0.06 & 0.18 & 12 \\
Benzo[b]fluoranthene & 0.9962 & $0.4-42$ & Passed & 0.12 & 0.40 & 13 \\
Benzo[a]pyrene & 0.9996 & $0.4-42$ & Passed & 0.06 & 0.19 & 22 \\
\hline
\end{tabular}

*Differences for percentage of height compared to the peak of the lowest calibration point (CS1) of the peaks that elute at the retention time of the analytes in the procedural blank (PB) samples

The precision (repeatability and intermediate precision) of the analytical procedure was evaluated at close to the lowest level of the working range from naturally low contaminated milk samples rich in fat (3.0\%) that were spiked with a PAH standard solution in the content level of $0.25 \mu \mathrm{g} \mathrm{kg}^{-1}$. For the repeatability evaluation, three different spiked samples were analyzed on three different days as triplicate. In order to verify homogeneity of variances using the Cochran test, all obtained results were evaluated and passed for all data sets. For calculation of precision parameters (repeatability and intermediate precision), analysis of variance (ANOVA) was used and the obtained results expressed such as $\%$ RSD (relative standard deviation). The repeatability relative standard deviations $\left(\mathrm{RSD}_{\mathrm{r}}\right)$ were obtained below $15 \%$ for each of analytes. For evaluation of the intermediate precision, three spiked samples in three independent analysis sequences that spread out during the period of 1 month were analyzed as triplicate. For each of analytes, the intermediate precision relative standard deviations $\left(\mathrm{RSD}_{\mathrm{IP}}\right)$ were below $20 \%$. Table 2 shows all obtained results for repeatability and intermediate precision at the low level $(0.25$ $\mu \mathrm{g} \mathrm{kg}^{-1}$ ) of PAHs spiked to milk samples.

Additionally, Precision was defined as $\mathrm{HORRAT}_{\mathrm{r}}$ and HORRAT $_{R}$ values according to Regulation of European Commission, No. 836/2011. HORRAT ${ }_{r}$ was meaning in there as the observed relative standard deviation $\left(\% \mathrm{RSD}_{\mathrm{r}}\right)$ under repeatability conditions divided by the RSDr value estimated from the Horwitz equation, as well as the HORRAT $_{R}$ values, meaning the observed $\mathrm{RSD}_{\mathrm{IP}}$ (relative intermediate precision values) value under reproducibility divided by the $\mathrm{RSD}_{\mathrm{R}}$ value calculated from the Horwitz equation (see Table 2). If the HORRAT values are below crucial value of 2.0, applied analytical methods may be acceptable for fit-for-purpose [22]. All four PAH analyte fulfilled these criteria. 
Table 2. Repeatability relative standard deviation $\left(\mathrm{RSD}_{\mathrm{r}}\right)$, intermediate precision relative standard deviation ( $\left.\mathrm{RSD}_{\mathrm{IP}}\right)$, HORRAT values for repeatability $\left(\mathrm{HOR}_{\mathrm{r}}\right)$ and reproducibility $\left(\mathrm{HOR}_{\mathrm{R}}\right)$, and relative expanded measurement uncertainty $(\mathrm{U})$ for the determination of four European Union marker PAHs in milk samples rich in fat (3.0\%) which were spiked with $0.25 \mu \mathrm{g} \mathrm{kg}$ ${ }^{1}$ of each of the four analyte.

\begin{tabular}{lccccc}
\hline \multicolumn{1}{c}{ PAHs } & RSD $_{\mathrm{r}} \%$ & $\mathrm{RSD}_{\mathrm{IP}} \%$ & $\mathrm{HOR}_{\mathrm{r}}$ & $\mathrm{HOR}_{\mathrm{R}}$ & $\mathrm{U}(\mathrm{k}=2)$ \\
\hline Benz[a]anthracene & 6.8 & 13.3 & 0.5 & 0.6 & 16 \\
Chrysene & 6.8 & 11.6 & 0.5 & 0.5 & 14 \\
Benzo[b]fluoranthene & 6.7 & 9.2 & 0.5 & 0.4 & 11 \\
Benzo[a]pyrene & 6.8 & 16.3 & 0.5 & 0.7 & 19 \\
\hline
\end{tabular}

For the recovery, five different spiked and unspiked control samples for skimmed and whole milk samples were used and each of these recovery samples was analyzed as triplicate by using the all analytical procedure. The average recoveries (Table 3) were calculated using the differences of the measurement results between unspiked control samples and the spiked samples in which each compound spiked $0.25 \mu \mathrm{g} \mathrm{kg}^{-1}$ in the total amount. The average recoveries of individual PAHs and their relative standard deviations (\% RSDs) were found in the range between $87 \%$ and $92 \%$, with RSDs between $7 \%$ and $9 \%$ for skimmed milk sample, and in the range between $76 \%$ and $86 \%$, with RSDs between $9 \%$ and $14 \%$ for whole milk sample, respectively. The results for recovery of milk samples are shown in Table 3.

Table 3. Mean recoveries (\%), Standard deviations (SD) and spiking level of polycyclic aromatic hydrocarbons (PAHs) added to whole and skimmed UHT milk.

\begin{tabular}{lccccc}
\hline \multicolumn{1}{c}{} & \multicolumn{2}{c}{ Milk (skimmed) } & \multicolumn{2}{c}{ Milk (whole) } \\
\hline \multicolumn{1}{c}{ PAHs } & Spiking level $\left(\mu \mathrm{g} \mathrm{kg}{ }^{-1}\right)$ & Recovery $(\%)$ & SD $(\%)$ & Recovery $(\%)$ & SD $(\%)$ \\
\hline Benz[a]anthracene & 0.25 & 88 & 8 & 82 & 9 \\
Chrysene & 0.25 & 90 & 9 & 81 & 14 \\
Benzo[b]fluoranthene & 0.25 & 87 & 8 & 76 & 13 \\
Benzo[a]pyrene & 0.25 & 92 & 7 & 86 & 10 \\
\hline
\end{tabular}

The uncertainty of the method was also calculated based on the Eurachem/Citac Guidelines [18]. For estimation of measurement uncertainty, the law of error propagation was used and it was given as combined uncertainty. The contributors of combined uncertainty were considered focusing on these factors: native PAH standard solutions for instrument calibration, uncertainty was observed for the preparation of test materials and uncertainty of the preparation of spiking solutions were taken into account and the uncertainty contribution arising from instrument calibration, uncertainty stemming from the precision of the analyses, and uncertainty of bias were evaluated as important factors. For the calculations, the measurement data at the $0.1 \mu \mathrm{g} \mathrm{kg}^{-1}$ content level were used. As seen in the Table 2, the calculated relative expanded uncertainty (U) was ranged from $11 \%$ to $19 \%$ for the four EU marker PAHs.

\subsection{Analysis of commercial samples}

In this study, liquid-liquid extraction a preconcentration procedure and HPLC-fluorescence detection was applied in order to determine the ratio and level of the 4PAHs in totally twentyseven commercial milk samples obtained from the Turkish market. Particularly, each type of milk samples i.e. pasteurized and UHT (semi-skimmed, skimmed and whole) cow and goat's milk and also raw milks from local farm, was investigated. Some of plant milk samples such as coconut, almond, and soya milk were also examined.

The data presented in Table 4, contains a summary of all analytical results for different kind of milks. It indicated that the concentrations of PAHs in samples varied according to nature of the samples, their fat content and heat treatment processing. 
The highest mean concentration of 4PAHs found in whole UHT milk samples was $0.84 \pm 0.57 \mu \mathrm{g}$ $\mathrm{kg}^{-1}$ while the lowest in raw milk samples is 0.10 $\pm 0.06 \mu \mathrm{g} \mathrm{kg}^{-1}$. These results were in parallel with the literature studies indicating the lower PAH level in raw milk when compared with the UHT and pasteurized milk [11-15]. On the other hand, these 4PAHS' mean concentrations were significantly lower from the studies of Girelli et al. and Naccari et al., which were $18.60 \pm 2.92 \mu \mathrm{g}$ $\mathrm{kg}^{-1}$ and $7.75 \mu \mathrm{g} \mathrm{kg}^{-1}$, respectively [11,12].

Furthermore, the data showed that Chrysene (CHR) was the most widespread PAH within the all analyzed samples with the average concentration between $0.10 \pm 0.06$ and $0.41 \pm 0.11$ $\mu \mathrm{g} \mathrm{kg}^{-1}$. Minimum and maximum $\mathrm{CHR}$ concentrations were found as 0.06 and $0.58 \mu \mathrm{g} \mathrm{kg}^{-}$ ${ }^{1}$ for the raw milk and whole UHT milk samples, respectively.

Benz[a]anthracene

$(\mathrm{BaA})$ concentration was in the range of 0.08 to $0.82 \mu \mathrm{g}$ $\mathrm{kg}^{-1}$ whereas benzo[a]pyrene $(\mathrm{BaP})$ concentration varied from 0.12 to $0.82 \mu \mathrm{g} \mathrm{kg}{ }^{-1}$. Benzo[b] fluoranthene $(\mathrm{BbF})$ was not detected in any kind of analyzed samples.

It is obvious that these values are lower than $1 \mu \mathrm{g}$ $\mathrm{kg}^{-1}$ which is the maximum level settled in the European Commission Regulation (EC) No $835 / 2011$ [22] for in infant milk and follow-on milk.

After evaluation of the levels of PAHs in the raw, pasteurized and, UHT milks and as well as considering studies in literature that they are made for popular milk brands in different countries, it can be easily seen that the heat treatment used in processing techniques of milk influences $\mathrm{PAH}$ formation, as reported by Naccari et al. [12] and Girelli et all. [11].

Table 4. Mean, Maximum, and Minimum levels of PAHs, expressed as mean \pm SD ( $\mu \mathrm{g} / \mathrm{kg}-1 \mathrm{milk})$ of the analyzed samples of raw, pasteurized and UHT skimmed, semi-skimmed, and whole and plant milk from popular Turkish brands.

\begin{tabular}{|c|c|c|c|c|c|c|c|}
\hline & & $\begin{array}{c}\text { Raw Milk } \\
\text { Samples }(\mathrm{N}=2) \\
\left(\mu \mathrm{kg}^{-1} \text { of }\right.\end{array}$ & $\begin{array}{c}\text { Pasteurized milk } \\
(\mathrm{N}=5) \\
\text { (ug } \mathrm{kg}^{-1} \text { of millk) }\end{array}$ & \multicolumn{3}{|c|}{$\begin{array}{c}\text { UHT } \\
\text { ( } \mu \mathrm{g} \mathrm{kg}^{-1} \text { of milk) }\end{array}$} & \multirow{2}{*}{$\begin{array}{l}\text { Plant milk } \\
(\mathrm{N}=3) \\
\text { ( } \mu \mathrm{g} \mathrm{kg}^{-1} \text { of } \\
\text { milk) }\end{array}$} \\
\hline PAHs & & & & $\begin{array}{l}\text { Skimmed } \\
(\mathrm{N}=3)\end{array}$ & $\begin{array}{l}\text { Semi-skimmed } \\
(N=4)\end{array}$ & $\begin{array}{l}\text { Whole } \\
(\mathrm{N}=10)\end{array}$ & \\
\hline \multirow{3}{*}{$\begin{array}{l}\text { Benz }[\mathrm{a}] \text { anthracene } \\
(\mathrm{BaA})\end{array}$} & Mean \pm SD & n.d & $0.48 \pm 0.07$ & $0.21 \pm 0.07$ & $0.35 \pm 0.11$ & $0.32 \pm 0.24$ & 0.05 \\
\hline & Min. & n.d & 0.43 & 0.16 & 0.22 & 0.08 & 0.05 \\
\hline & Max. & n.d & 0.52 & 0.26 & 0.42 & 0.82 & 0.05 \\
\hline \multirow{3}{*}{ Chrysene (CHR) } & Mean \pm SD & $0.10 \pm 0.06$ & $0.27 \pm 0.07$ & $0.27 \pm 0.19$ & $0.20 \pm 0.07$ & $0.41 \pm 0.11$ & n.d \\
\hline & Min. & 0.06 & 0.18 & 0.15 & 0.14 & 0.25 & n.d \\
\hline & Max. & 0.14 & 0.36 & 0.49 & 0.30 & 0.58 & n.d \\
\hline \multirow{3}{*}{$\begin{array}{l}\text { Benzo [b] fluoranthene } \\
\text { (BbF) }\end{array}$} & Mean \pm SD & n.d & n.d & n.d & n.d & n.d & n.d \\
\hline & Min. & n.d & n.d & n.d & n.d & n.d & n.d \\
\hline & Max. & n.d & n.d & n.d & n.d & n.d & n.d \\
\hline \multirow{3}{*}{ Benzo[a]pyrene (BaP) } & Mean \pm SD & n.d & $0.24 \pm 0.09$ & $0.40 \pm 0.03$ & $0.29 \pm 0.06$ & $0.48 \pm 0.26$ & $0.28 \pm 0.28$ \\
\hline & Min. & n.d & 0.12 & 0.38 & 0.25 & 0.35 & 0.08 \\
\hline & Max. & n.d & 0.35 & 0.42 & 0.33 & 0.82 & 0.47 \\
\hline Total 4 EU PAHs & Mean \pm SD & $0.10 \pm 0.06$ & $0.71 \pm 0.33$ & $0.68 \pm 0.43$ & $0.61 \pm 0.11$ & $0.84 \pm 0.57$ & $0.20 \pm 0.28$ \\
\hline
\end{tabular}

Note: n.d., Not detectable

\section{CONCLUSIONS}

The contamination level of 4 EU PAHs in 27 kinds of milk samples commercialized in Turkey were determined using a sensitive HPLC method.

The obtained results showed that mean contamination level for 4 marker EU PAHs in individual samples were ranged from $0.10 \pm 0.06$ to $0.84 \pm 0.57 \mu \mathrm{g} \mathrm{kg}^{-1}$. The highest mean levels of 4 EU PAHs were detected in whole UHT milk samples $\left(0.84 \pm 0.57 \mu \mathrm{g} \mathrm{kg}^{-1}\right)$ followed by pasteurized milk $\left(0.71 \pm 0.33 \mu \mathrm{g} \mathrm{kg}^{-1}\right)$. The lowest level was detected in raw milk samples $(0.10$ $\left.\pm 0.06 \mu \mathrm{g} \mathrm{kg}^{-1}\right)$.

The present study was the first attempt to provide baseline information of potential health risk of 
PAHs-containing milk samples, which could be useful for health management of the consumers in Turkey.

According to our survey, PAHs contamination has been well-controlled in Turkey during recent years; however, it can be said that all analyzed products fulfilled the European Union food law requirements (Commission Regulation (EU) No. 835/2011).

\section{ACKNOWLEDGEMENTS}

This work was supported by the Giresun University-Scientific Research Projects Unit (GRU-BAP) under grant FEN-BAP-A-200515-83.

\section{REFERENCES}

[1] SCF (Scientific Committee on Food), Polycyclic Aromatic Hydrocarbons Occurrence in foods, dietary exposure and health effects, Annex., (2002) A1-A194.

[2] SCF (Scientific Committee on Food), Opinion of the Scientific Committee on Food on the risks to human health of Polycyclic Aromatic Hydrocarbons in food, (2002) 1-84.

[3] Codex Committee on Food Additives and Contaminants (CCFAC), Discussion Paper on Polycyclic Aromatic Hydrocarbons (PAH) Contamination, Jt. Fao/Who Food Stand. Program., 17 (2005).

[4] Joint FAO/WHO expert Committee on Food Additives (JECFA), Summary and conclusions of the sixty-fourth meeting. (2005) 1-47.

[5] IARC, Some Non-heterocyclic Polycyclic Aromatic Hydrocarbons and Some Related Exposures, Iarc Monogr. Eval. Carcinog. Risks To Humans., 92 (2010) 1-868.

[6] IARC, A review of human carcinogens: chemical agents and related occupations, IARC Monogr. Eval. Carcinog. Risks to Humans. Vol. 100F (2012) 225-248.

[7] EC (European Commission), commission recommendation of 2005/108 of 4 February 2005 on the further investigation into the levels of polycyclic aromatic hydrocarbons in certain foods, Off. J. Eur. Union. L34 (2005) 43-45.

[8] EFSA (European Food Safety Authority), Findings of the EFSA Data Collection on Polycyclic Aromatic Hydrocarbons in Food, EFSA J., 724 (2008) 1-55.

[9] EFSA (European Food Safety Authority),
Polycyclic Aromatic Hydrocarbons in Food. Scientific Opinion of the Panel on Contaminants in the Food Chain, EFSA J., 724 (2008) 1-114.

[10] EC (European Commission), commission regulation (EU) No 836/2011, Off. J. Eur. Union EN. 2011 (2011) 9-16.

[11] Girelli A.M., Sperati D., and Tarola A.M., Determination of polycyclic aromatic hydrocarbons in Italian milk by HPLC with fluorescence detection, Food Addit. Contam. Part A., 31 (2014) 703-710.

[12] Naccari C., Cristani M., Giofrè F., Ferrante M., Siracusa L., and Trombetta D., PAHs concentration in heat-treated milk samples, Food Res. Int., 44 (2011) 716-724.

[13] Chung T.L., Liao C.J., and Chen M.F., Comparison of liquid-liquid extraction and solid-phase extraction for the determination of polycyclic aromatic hydrocarbons in the milk of Taiwan, J. Taiwan Inst. Chem. Eng., 41 (2010) 178183.

[14] Aguinaga N., Campillo N., Viñas,P. and Hernández-Córdoba M., A headspace solid-phase microextraction procedure coupled with gas chromatography-mass spectrometry for the analysis of volatile polycyclic aromatic hydrocarbons in milk samples, Anal. Bioanal. Chem., 391 (2008) 753-758.

[15] Aguinaga N., Campillo N., Viñas P., and Hernández-Córdoba M., Determination of 16 polycyclic aromatic hydrocarbons in milk and related products using solidphase microextraction coupled to gas chromatography-mass spectrometry, Anal. Chim. Acta., 596 (2007) 285-290.

[16] DiScenza D.J., Lynch J., Verderame M., Smith M.A., and Levine M., CyclodextrinPromoted Fluorescence Detection of Aromatic Toxicants and Toxicant Metabolites in Commercial Milk Products, Food Anal. Methods., 11 (2018) 24192430.

[17] Eurachem Guide: The Fitness for Purpose of Analytical Methods - A Laboratory Guide to Method Validation and Related Topics, (2014) 1-70.

[18] EURACHEM/CITAC Guide CGQuantifying Uncertainty in Analytical Measurement. 2nd ed. (2000) 126.

[19] Mandel J., The statistical analysis of experimental data, Wiley \& Sons, New York (NY), (1964). 
[20] Kacmaz, S. Polycyclic aromatic hydrocarbons in cereal products on the Turkish market, Food Addit. Contam. Part B., 9 (2016) 191-197.

[21] Kacmaz S., Zelinkova Z., and Wenzl T., Rapid and sensitive method for the determination of four EU marker polycyclic aromatic hydrocarbons in cereal-based foods using isotope-dilution GC/MS, Food Addit. Contam. Part A Chem. Anal. Control. Expo. Risk Assess., 33 (2016) 631-638.

[22] EC (European Commission), Commission regulation (EU) No 835/2011 of 19 August 2011 amending Regulation (EC) No 1881/2006 as regards maximum levels for polycyclic aromatic hydrocarbons in foodstuffs, Off. J. Eur. Union., (2011) 4-8. 